\title{
Effect of carbide powder characteristics on the PVT behavior of powder injection molding compounds
}

\author{
Berenika Hausnerova ${ }^{a, *}$, Lucie Cucova b, Andrea Sorrentino c,d
}

\author{
${ }^{a}$ Centre of Polymer Systems, Department of Production Engineering, Tomas Bata University in Zlín, nám. \\ T.G. Masaryka 5555, 76001 Zlin, Czech Republic \\ ${ }^{b}$ Centre of Polymer Systems, Polymer Centre, Tomas Bata University in Zlín, nám. T.G. Masaryka 5555, 760 \\ 01 Zlin, Czech Republic \\ ${ }^{c}$ Institute for Composite and Biomedical Materials, National Research Council, Piazzale Enrico Fermi 1, \\ 80055 Portici, Italy \\ ${ }^{d}$ Department of Industrial Engineering, University of Salerno, via Ponte don Melillo, I-84084 Fisciano \\ (Salerno), Italy
}

\begin{abstract}
Effect of powder concentration and particle size distribution of highly filled cemented carbide compounds on their pressure-volume-temperature (PVT) characteristics and thermal properties was investigated. PVT data of compounds containing up to $50 \mathrm{vol} . \%$ of powder evaluated on a high-pressure mercury dilatometer reveals that the pressure influences both detected phase transitions, but it causes a different effect on the melting and crystallization of the material only for the higher transition (corresponding to binder components with melting temperatures 100 and $107^{\circ} \mathrm{C}$ ). The discrepancies in specific volumes at an applied pressure diminish with increasing powder content, whereas melting temperatures - derived from differential scanning calorimetry - remain unaffected. Volumetric thermal expansion coefficient and compressibility are linearly and exponentially, respectively, dependent on pressure. Further, the variance in the particle size distributions of carbide compounds resulted in shifts in both volumetric thermal expansion coefficients and compressibility values.
\end{abstract}

(C) 2013 Elsevier B.V. All rights reserved.

\section{Keywords}

Pressure-volume-temperature characteristics, High-pressure mercury dilatometer, Particle size distribution, Powder injection molding, Binder, Cemented carbides

\footnotetext{
* Corresponding author. Tel.: +420 576035166; fax: +420 576031444.

E-mail address: hausnerova@ft.utb.cz (B. Hausnerova).

0032-5910/\$ - see front matter (C) 2013 Elsevier B.V. All rights reserved. http://dx.doi.org/10.1016/j.powtec.2013.01.067
} 


\section{Introduction}

Powder injection molding (PIM) has been used in the metal and ceramic industry since the 1970's [1]. The technology combining polymer processing and metallurgy represents an effective alternative to machining and investment casting in the production of small, complex-shaped metal and ceramic parts.

Although PIM has a great potential in medical, automotive, IT, telecommunication, and consumer sectors, its mass implementation on the market is still limited by a number of quality issues (e.g. separation of powder and binder during the injection molding step resulting in an inhomogeneous structure of sintered parts, and non-sophisticated set-up of optimum powder/binder ratio, or binder contamination of parts made of reactive materials) arising from the process and material complexity.

One of the process channel points requiring further clarification and optimization is the flow of highly filled feedstocks into mold cavities, where the solution consists of a successful simulation approach based on reliable experimental data. Since PIM is a high-pressure molding process, flow behavior and compressibility (pressure-volume-temperature data) of powder and polymer-based binder in a pressurized melt stage are key variables for the assessment of processing conditions necessary for the production of defect-free injection molded parts. Currently, such studies are reported scarcely.

In this respect, Persson et al. [2] studied the thermal properties of 40, 50 and 60 vol. $\% 420$ stainless steel based compounds on a PVT-100 (SWO, Germany) device. Regardless of powder concentration, the transition zones corresponding to the particular organic components of a binder derived from the PVT plots revealed the melting temperature shift from 62 to $66^{\circ} \mathrm{C}$ as pressure varied from 150 to $350 \mathrm{MPa}$. Wei et al. [3] investigated the pressure effects during the injection molding process using the same tool (PVT-100) for 85 wt.\% alumina in a paraffin wax based binder at pressures from 0.1 to $120 \mathrm{MPa}$ with the similar results.

Greene and Heaney [4] determined thermal behavior of 61.1 vol.\% carbonyl iron filled in a wax/polymer binder. The average volumetric shrinkage obtained from PVT measurements was compared with that predicted by a modified two-domain Tait PVT model. The model represents a mathematical fitting of a specific volume as a function of pressure and temperature. The results of the study proved that the calculated shrinkage and hold pressure could be used to effectively control dimensions of the final sintered components. Boehme et al. [5] measured coefficient of thermal expansion and curing shrinkage for two (vitreous silica and carbon black) highly-filled (82-94 wt.\%) resins. Crosslinking kinetic was evaluated using DSC and PVT. The experimental data of curing shrinkage during crosslinking, quantified via decrease of specific volume, was precisely fitted with a Tait model.

Binet et al. [6] studied Theological, PVT and thermal properties of 65 vol.\% 316L stainless steel in a three component binder (polyethylene, wax and lubricant). The specific heat capacity showed two peaks at about 56 and $135{ }^{\circ} \mathrm{C}$, the thermal conductivity of feedstock $\left(1.0 \mathrm{~W} / \mathrm{m}^{\circ} \mathrm{C}\right)$ was calculated from Rayleigh-Devries model using thermal conductivities of powder $\left(17.0 \mathrm{~W} / \mathrm{m}^{\circ} \mathrm{C}\right)$ and binder $(0.15$ $\mathrm{W} / \mathrm{m}^{\circ} \mathrm{C}$ ) [7]. The two-domain Tait PVT model was used for determination of the compressibility of feedstock, and the genetic algorithm was employed to fit the viscosity and specific volume characteristics at selected pressures. The experimentally evaluated data were compared with those derived from mathematical models, resulting in a Moldflow simulation of a case study item.

Laddha et al. [8] reported the study of flow and thermal properties of alumina (56 vol.\%) with in-house produced and commercial feedstocks. Gnomix equipment was used for PVT measurements to under- 
stand the compression and temperature effects during the injection molding cycle and obtained data in the range of pressure from 0 to $500 \mathrm{MPa}$ up to $200{ }^{\circ} \mathrm{C}$ were fitted with Tait equation. With the same apparatus, the effect of filler concentration on glass transition temperature obtained from PVT data was considered by Chandra et al. [9] for 20 and 40 vol.\% lead titanate in PMMA matrix. Transition temperature was shifted to higher values as filler content decreased, and thermal expansion coefficient also changed, enhanced at high pressure (up to $200 \mathrm{MPa}$ ).

As we have shown recently [10-12] in the papers reporting pressure and temperature dependent flow properties of cemented carbide compounds, it is not only powder loading, but also powder particle size distribution and mean particle size influencing considerably a bulk compressibility of PIM compounds. Therefore, the aim of this research is to evaluate the influence of such powder parameters on pressurevolume-temperature behavior of PIM compounds.

\section{Experimental}

\subsection{Materials}

The experiments were carried out on PIM compounds based on tungsten carbide ( $>93 \%)$, and cobalt (6\%) powder (Sylvania Tungsten, Czech Republic). Four grades, differing in their particle size distribution and abbreviated $10 \mathrm{U}, 17 \mathrm{~S}, 37 \mathrm{~S}$, and $75 \mathrm{H}$, were investigated. Shape of the particles was irregular (Fig. 1), particle size distributions relatively broad, mean diameters $1.24 \mu \mathrm{m}$ for both $10 \mathrm{U}$ and $17 \mathrm{~S}$ (the powders differ in the shape of the particle size distribution curves [13]), $3.32 \mu \mathrm{m}$ in the case of $37 \mathrm{~S}$ and $7.38 \mu \mathrm{m}$ for $75 \mathrm{H}$ (Table 1).

Polymeric binder used for compounds preparation consisted 53 wt.\% low-density polyethylene (Lacqtene, Atochem), 26 wt.\% paraffin wax and 21 wt.\% ethylene-acrylic acid block copolymer (Ex 225, ExxonMobil Chemicals).

\begin{tabular}{lccccc}
\hline $\begin{array}{l}\text { Table 1 } \\
\text { Characteristics of cemented carbide powders used in compounds investigated. }\end{array}$ \\
\hline Powder & & $10 \mathrm{U}$ & $17 \mathrm{~S}$ & $37 \mathrm{~S}$ & $75 \mathrm{H}$ \\
\hline Shape & & Fig. 1a & Fig. 1b & Fig. 1c & Fig. 1d \\
Particle size $(\mu \mathrm{m})$ & D10 & 0.45 & 0.43 & 1.04 & 2.19 \\
& D50 & 1.11 & 1.36 & 3.80 & 15.38 \\
& D90 & 3.75 & 2.71 & 7.14 & 28.06 \\
Density $(\mathrm{g} / \mathrm{cm} 3)$ & Scott & 2.64 & 2.67 & 4.36 & 8.46 \\
& Tap & 4.85 & 4.85 & 6.82 & 9.22 \\
\hline
\end{tabular}

\subsection{Compounding}

Highly filled cemented carbide compounds (30 and 50 vol.\%) were prepared on a laboratory kneader (Brabender Plasticorder, PL-2000-6, mixer type W 50E) at $150{ }^{\circ} \mathrm{C}$ and $40 \mathrm{rpm}$. The mixing chamber was filled in $70-80 \%$ of its volume. Firstly, a small amount of polymeric binder was preheated in a mixing chamber for about $1 \mathrm{~min}$. Then, after interchangeable addition of the remaining binder and powder, the mixing was carried out until a steady torque was achieved. 


\subsection{Methods}

Density of investigated feedstocks was evaluated from samples (about $2.55 \mathrm{~cm}^{3}$ in volumes) prepared in an injection molding machine (MINIMAX MOLDER CS-183 MMX, Custom Scientific Instruments, USA) with Archimedes method in three different liquids - distilled water $\left(1.000 \mathrm{~g} / \mathrm{cm}^{3}\right)$, methyl alcohol $\left(0.792 \mathrm{~g} / \mathrm{cm}^{3}\right)$ and hexane $\left(0.659 \mathrm{~g} / \mathrm{cm}^{3}\right)$. The obtained density values (averages of three measurements) are summarized in Table 2.

Atomic force microscopy (AFM) was carried out at ambient conditions (NanoScope III multimode AFM (Digital Instruments), Santa Barbara (CA)) using microfabricated silicon tips/cantilevers. The images were recorded simultaneously in height and in amplitude.

Differential scanning calorimetry (DSC) tests were carried out on a DSC30 (Mettler, USA) apparatus under nitrogen atmosphere. The samples were heated from 25 to $210{ }^{\circ} \mathrm{C}(298$ to $483 \mathrm{~K})$ at $1{ }^{\circ} \mathrm{C} / \mathrm{min}$, kept at $210^{\circ} \mathrm{C}(483 \mathrm{~K})$ for $1 \mathrm{~min}$, and then cooled down to $25^{\circ} \mathrm{C}(298 \mathrm{~K})$ at the same rate.
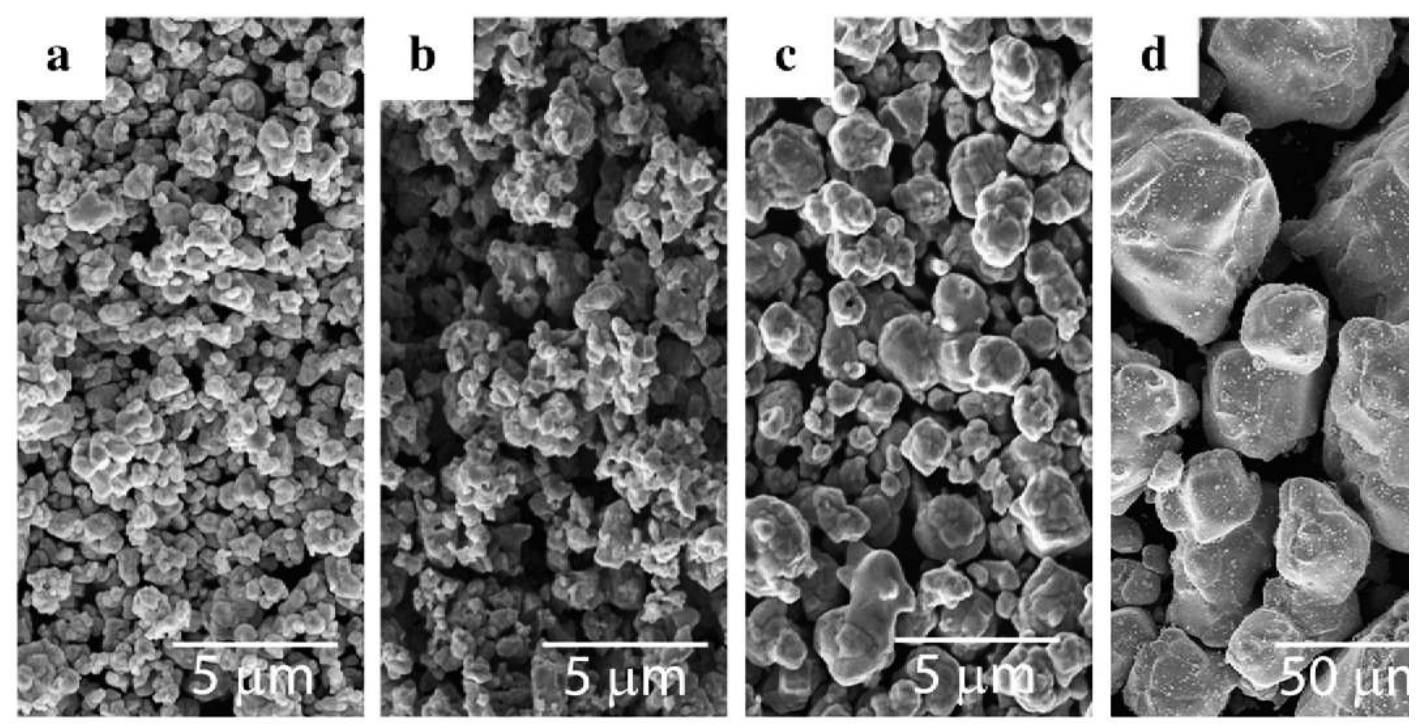

Fig. 1. SEM of cemented carbide powders with mean particle sizes ordered as follows $10 \mathrm{U}<17 \mathrm{~S}<37 \mathrm{~S}<75 \mathrm{H}$.

Table 2

Compositions and densities of cemented carbide compounds.

\begin{tabular}{lllllll}
\hline Powder & $10 \mathrm{U}$ & & $17 \mathrm{~S}$ & $37 \mathrm{~S}$ & $75 \mathrm{H}$ & \\
\hline Sample code & $10 \mathrm{U}-30$ & $10 \mathrm{U}-50$ & $17 \mathrm{~S}-50$ & $37 \mathrm{~S}-50$ & $75 \mathrm{H}-30$ & $75 \mathrm{H}-50$ \\
Powder content (vol.\%) & 30 & 50 & 50 & 50 & 30 & 50 \\
Density $\left(\mathrm{g} / \mathrm{cm}^{3}\right)$ & 5.107 & 8.073 & 8.117 & 8.123 & 4.929 & 8.372 \\
\hline
\end{tabular}


Pressure-volume-temperature (PVT) behavior was investigated on a fully automated high-pressure mercury dilatometer (Gnomix, USA) in a pressure range 10-175 MPa at temperatures from 25 to $210^{\circ} \mathrm{C}$ ( 298 to $483 \mathrm{~K}$ ). Heating and cooling rates of $1{ }^{\circ} \mathrm{C} / \mathrm{min}$ were selected for the experimental runs. The sample in the nickel cup (formed with a special mandrel) was enclosed in the cell and the space not occupied with the sample was filled with a confining fluid (mercury) under vacuum. The greatest advantage of this technique (in contrast to e.g. SWO apparatus) is that the sample is under hydrostatic pressure at all times (solid, molten, and re-solidified states).

\section{Results and discussion}

\subsection{AFM characterization}

The morphology of the molded samples was investigated by Atomic force microscopy (AFM). Fig. 2 shows the micrograph of the fracture surface of the specimen filled with $50 \mathrm{vol} \%$ of filler. It can be clearly seen (Fig. 2) that the binder and powder are of good compatibility and the mixture is homogeneous in all samples. The micrographs show no agglomeration of carbide particles.

For the injection molding of powder filled feedstocks, a homogeneous distribution of powder particles is crucial in order to avoid cracks, porosity or distortions in the produced parts. The high shear rates in injection molding may lead to powder binder segregation. This may lead to non-homogeneous binder extraction during the debinding step or to an anisotropic shrinkage during the sintering step resulting in cracks or deformations. A homogeneous distribution of the powder particles and binder in feedstock is important, as it helps to minimize segregation in the injection stage and then to obtain an isotropic shrinkage after sintering.

Fig. 2 shows that all samples present fine microstructures with very low void ratio. As expected, the sample made with large particle dimensions $(75 \mathrm{H})$ has less homogenous microstructure with the corresponding void ratio.

\subsection{DSC characterization}

In Fig. 3, the DSC curves in heating scan of the various samples are shown. Two melting transitions at $328 \mathrm{~K}\left(\approx 55{ }^{\circ} \mathrm{C}\right)$ and $374 \mathrm{~K}\left(\approx 101{ }^{\circ} \mathrm{C}\right)$ are visible in all samples. The first one corresponds to the component with the lowest melting temperature - paraffin wax $\left(329 \mathrm{~K} \approx 56{ }^{\circ} \mathrm{C}\right)$. The melting temperatures of low-density polyethylene $\left(380 \mathrm{~K} \approx 107^{\circ} \mathrm{C}\right)$ and ethylene-acrylic acid block copolymer $\left(373 \mathrm{~K} \approx 100{ }^{\circ} \mathrm{C}\right.$ ) are rather close to each other, and therefore coincide into one transition manifested as the second peak. At approximately $338 \mathrm{~K}\left(\approx 65^{\circ} \mathrm{C}\right)$, a weak endothermal transition can be detected in all cases. The peak-like shape of the endothermal signals implies that the signal is not caused by a glass transition. The peaks have a similar intensity in all samples, and probably can be attributed to the melting of a small fraction of high molecular weight wax.

Also in the subsequent cooling are evident three phase transitions corresponding to the crystallization of three phases present in the polymer matrix. The corresponding peaks are located at about $365 \mathrm{~K}, 328 \mathrm{~K}$ and $324 \mathrm{~K}$, respectively. In that case, the main difference between the samples is represented by the crystallization peak at higher temperature. The binder shows a sharp phase transition centered about 1-2 K lower than that of the other samples. Probably, the interface between the metallic particles and the polymer matrix help the heterogeneous nucleation at high temperature. As expected, that effect is more evident for the sample with smaller particles, due to the high number of interfaces present. On the other hand, the presence of a high concentration of filler acts as a barrier for the subsequent growth of crystal 

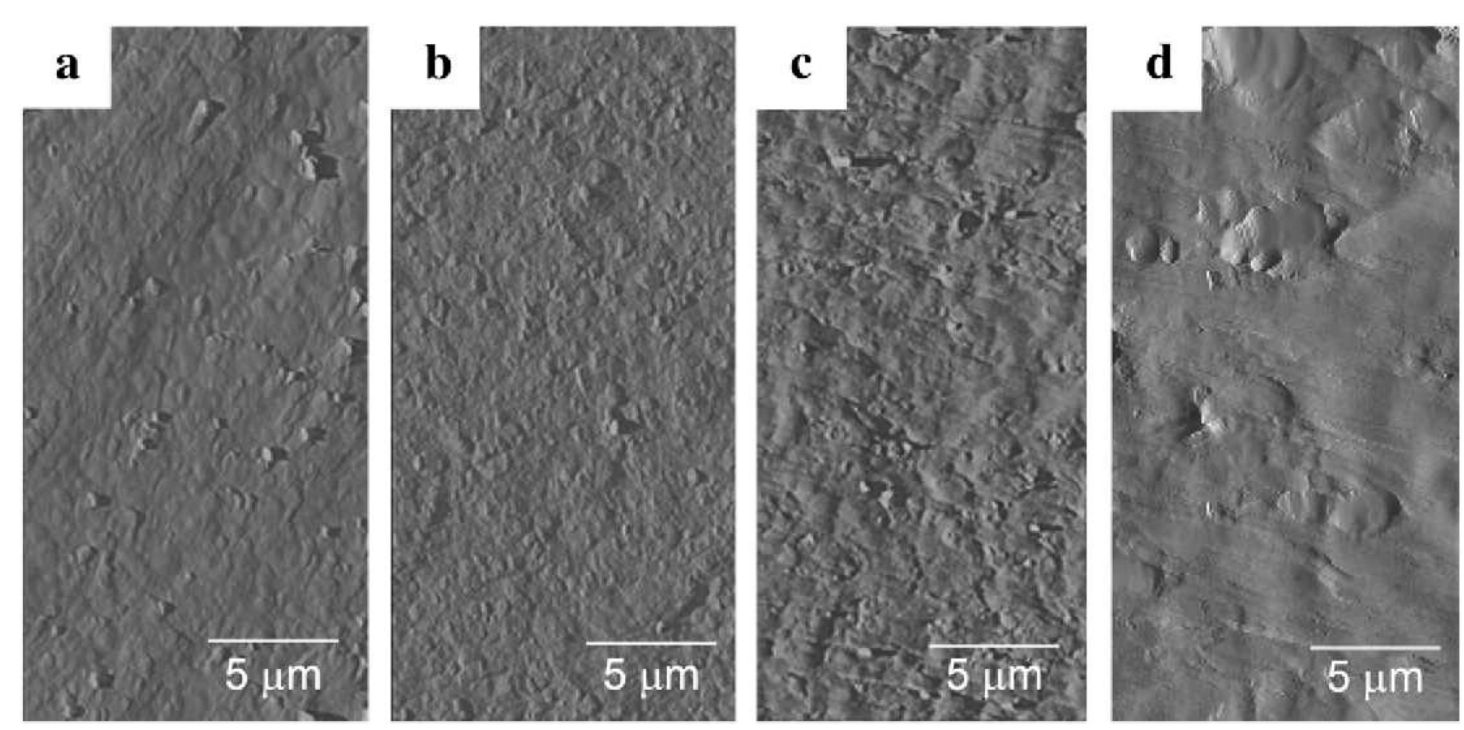

Fig. 2. Tapping mode AFM amplitude images of the filled feedstocks.

into the polymer matrix. It is evidenced by the broad crystallization peak shown by the composites. Also in that case, the smaller particles have the higher effect.

\subsection{PVT characterization}

Pressure-volume-temperature (PVT) behavior of the polymer components can be revealed from Fig. 4, where they are reported as the isobaric curves in both cooling and heating mode. In that case, the melting and/or the crystallization temperatures of the samples are indicated by an inflection point in the corresponding specific volume-temperature curves. Similarly, from the differential scanning calorimetry it is evident that the binder shows two phase transitions. The melting transition at lower temperature appears much less pronounced compared with the DSC measurements, whereas the small peak at $338 \mathrm{~K}$ ( $328 \mathrm{~K}$ in cooling mode) evidenced by DSC curves cannot be distinguished from the lower temperature melting peak.
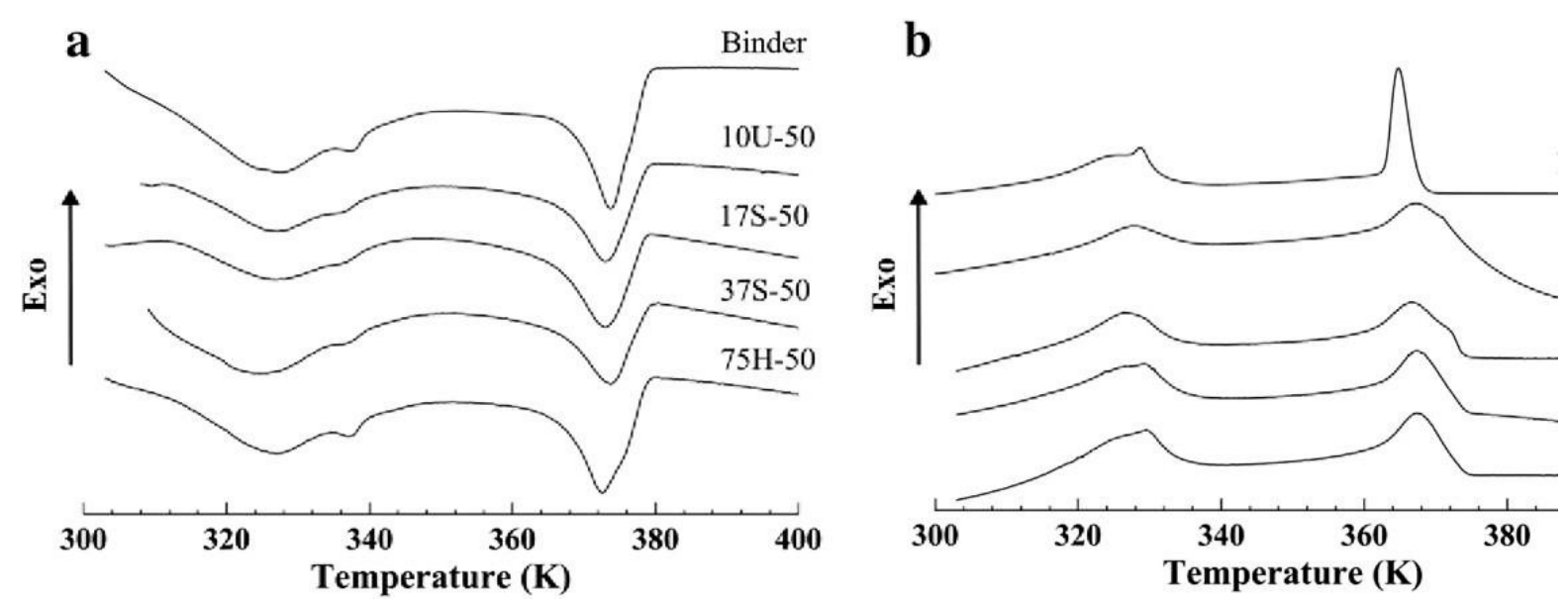

Fig. 3. DSC traces in a) heating and b) cooling mode of the various samples, measured with a heating rate of $1 \mathrm{~K} / \mathrm{min}$. 
PVT curves showing specific volumes of 10U-30 and 10U-50 samples as functions of temperature and pressure in both cooling and heating modes are depicted in Fig. 5. Transition temperatures for feedstocks filled with 30 vol.\% (10U-30) or 50 vol.\% (10U-50) of carbide powder (10U) are in the same positions with the respect to pressure and temperature. As expected, the lower values of specific volume correspond to the increasing amount of carbide powder in a feedstock, which is reflected during the injection molding process, where volume changes largely governed by polymer component become upon increasing powder content - less pronounced.

A more sensitive tool for the detection of phase transitions is obtained by plotting the thermal expansion coefficient, $\alpha$, instead of the specific volume, versus temperature. To that purpose, the derivative of the experimental logarithmic functions of the specific volumes with respect to the temperature, were calculated. In Fig. 6 the results for the neat binder, 10U-30 and 10U-50 samples are reported in cooling mode and at a constant pressure (100 MPa).

The plot clearly shows three different regions of behavior: I) first transition at $\mathrm{T}<350 \mathrm{~K}$ corresponding to the crystallization of paraffin, II) second transition at $350 \mathrm{~K}<\mathrm{T}<385 \mathrm{~K}$ corresponding to the crystallization of polyethylene and copolymer, III) a molten region at $\mathrm{T}>385 \mathrm{~K}$.

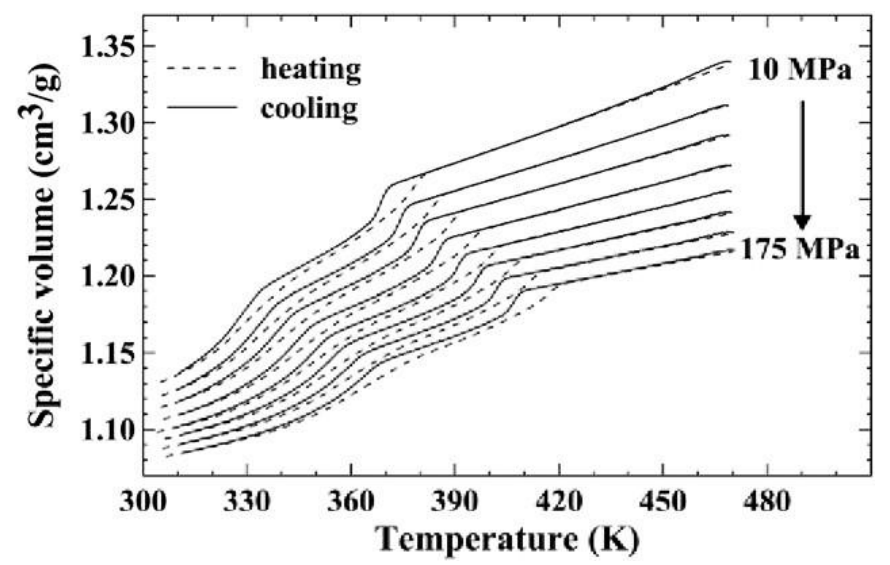

Fig. 4. Pressure-volume-temperature characteristic during heating and cooling regimes for the three-component polymeric binder.

In particular, for all the analyzed samples the region III seems to be characterized by T-independent values of a within the experimental standard errors.

An estimation of the crystallization temperature $T_{C}$ defined as the temperature at which the thermal expansion coefficient passes through a maximum was carried out for all samples at the different pressures. In Fig. 7, $T_{c 1}$ and $T_{c 2}$ versus pressure were first fitted by a linear regression, in accordance with the Clausius-Clapeyron equation (Eq. (1)):

$$
\frac{\partial T_{t r}}{\partial P}=\frac{\Delta V_{m}}{\Delta S_{m}}=T_{t r} \frac{\Delta V_{m}}{\Delta H_{m}}
$$

where $T_{t r}$ is the transition temperature at zero pressure; $\Delta V_{m}$ and $\Delta H_{m}$ are the volume and the enthalpy changes upon crystallization, respectively [14]. 
The following relations reproduce experimental data within $1{ }^{\circ} \mathrm{C}$ :

$$
\begin{aligned}
& T_{c 1}=0.23 * P+367.8 \\
& T_{c 2}=0.20 * P+328.3 .
\end{aligned}
$$

For both crystallization mechanisms, the slope $\mathrm{d} T / \mathrm{d} P$ is seemingly not affected by pressure up to 200 MPa.

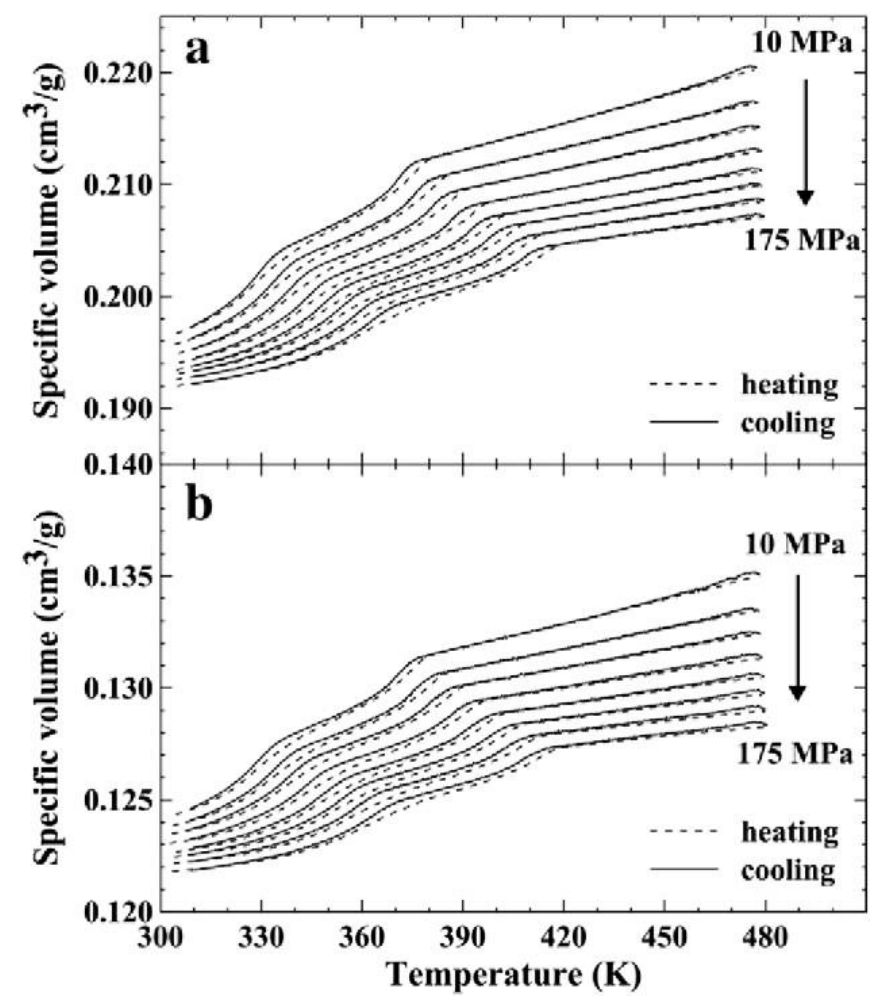

Fig. 5. Pressure-volume-temperature characteristic during heating and cooling regimes for highly filled cemented carbide compounds 10U-30 (a) and 10U-50 (b).

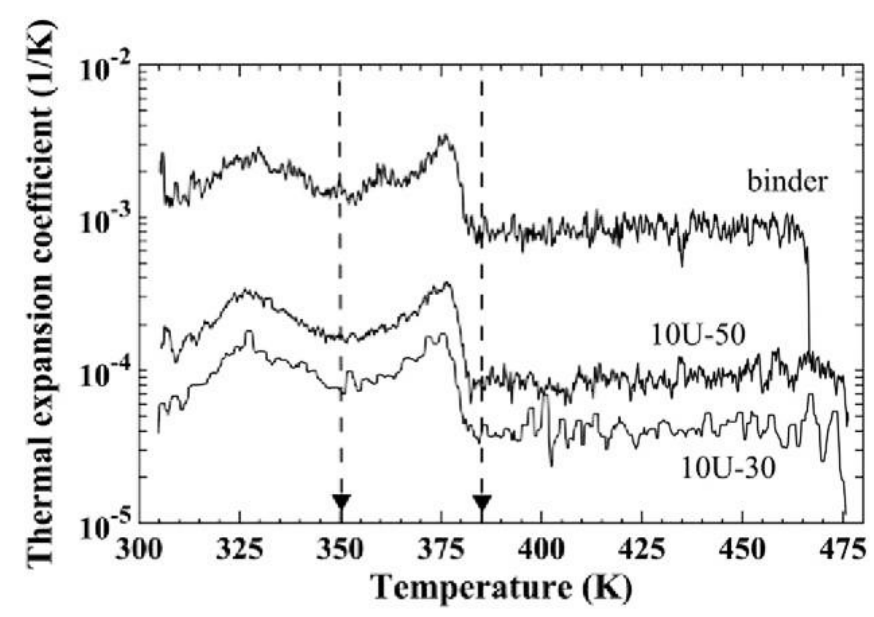

Fig. 6. Derivates of specific volumes of the reported samples as a function of temperature. 


\subsection{Compressibility and thermal expansion coefficient}

One of the principal reasons for performing pressure-volume-temperature (PVT) measurements is determining the thermal expansion and compressibility coefficients ( $\alpha$ and $\beta$, respectively):

$$
\alpha=\left(\frac{1}{v} \times \frac{\partial v}{\partial T}\right)_{P}=\left(\frac{\partial \ln v}{\partial T}\right)_{P} \quad \beta=\left(\frac{1}{v} \times \frac{\partial v}{\partial P}\right)_{T}=\left(\frac{\partial \ln v}{\partial P}\right)_{T}
$$

The coefficients defined in Eq. (4) were calculated by fitting the $\ln V$ data to a polynomial function of $P$ or $T$ and then differentiating the latter. With this approach the molten and solid phase data were separately fitted to a polynomial, and then differentiates the empirical relations.

\subsection{Compressibility and bulk modulus}

The compressibility is a fundamental material property that relates the volume change in a material to the imposed hydrostatic stress. The bulk modulus is a material property, which is often needed as an input in thermo-mechanical simulation software, and for elastic materials it is obtained as the inverse of the compressibility:

$$
\beta=-v\left(\frac{\partial P}{\partial v}\right)_{T}
$$

Compressibility of pure polymeric binder as well as compounds is decreasing exponentially with pressure; at high pressures it becomes almost pressure-independent (Fig. 8).

Persson et al. [2] described that the decreasing trend could be attributed to enhanced physical interactions between powder particles at higher powder loading and higher applied pressures. In the case depicted in Fig. 9 the compound based on powder with the smallest particles (10U - diameter at $10 \%, 0.45 \mu \mathrm{m} ; 90 \%, 3.75 \mu \mathrm{m})$ reveals the strongest sensitivity with respect to powder concentration as well as particle size distribution, which might support the above mentioned statement.

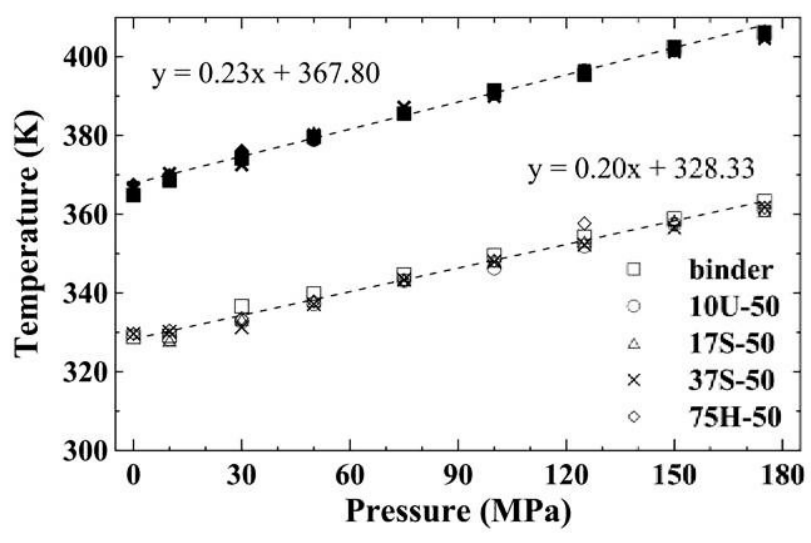

Fig. 7. Crystallization temperatures of various samples as a function of pressure. The dashed lines represent the linear fitting.

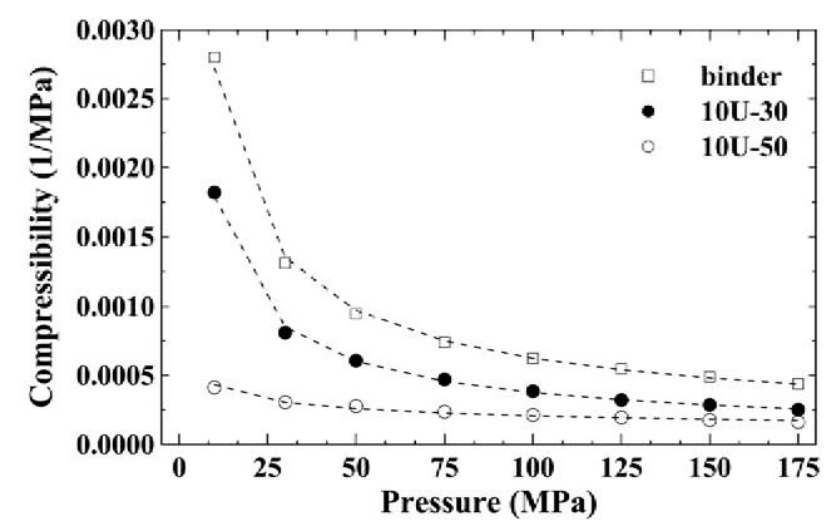

Fig. 8. Compressibility in the melting region as a function of pressure: effect of powder concentration. 
According to the powder content vs. hydrostatic pressure different states can be distinguished in feedstocks. At lower powder concentration, the distance between the filler particles increases considerably so that the particles cannot stabilize each other mechanically. As the concentration or the pressure increases, the particles come into closer contact and the binder is immobilized (i.e. cannot work as lubricant). Under pressure the excessive binder will move relative to the particle packing and the particles act as a filter through which the polymer molecules pass. In that case, the mechanical properties of the composites approach the filler values.

Hashin and Shtrikman [15,16] developed models based on the macroscopical isotropy and quasi-homogeneity of a composite, where the shape of the reinforcement is not a limiting factor. The model initially assumes a homogeneous and isotropic reference material in which the constituents are dispersed. Depending on whether the stiffness of the reference material is more or less than that of the reinforcement, the upper and lower boundaries are calculated as:

$$
\begin{aligned}
& K^{u}=K_{f}+\frac{1-\phi}{\frac{1}{K_{m}-K_{f}}+\frac{3 \phi}{\left(3 K_{f}+4 G_{p}\right)}} \\
& K^{1}=K_{m}+\frac{\phi}{\frac{1}{K_{p}-K_{m}}+\frac{3(1-\phi)}{\left(3 K_{m}+4 G_{m}\right)}}
\end{aligned}
$$

where subscripts $u$ and $l$ refer to the upper and lower boundary, respectively, $K_{f}$ is the bulk modulus of the filler, $G_{p}$ is the shear modulus of the filler, $K_{m}$ is the bulk modulus of the matrix, $G_{m}$ stands for the shear modulus of the matrix, and $K$ is the bulk modulus of the composite. In Table 1 the material properties of the filler used to estimate the composite properties are reported.

The lower boundary of the Hashin and Shtrikman model $[15,16]$ assumes that there is no stress transfer between reinforcement and matrix through interfaces. On the contrary, the upper boundary predicts a high affinity between matrix and filler considering the presence of interfacial bonding. As shown in Fig. 10 , the bulk moduli of the tested samples match very well with the lower bound of the model indicating that in the melting region the stress transfer between the powder and the polymer binder can be neglected.

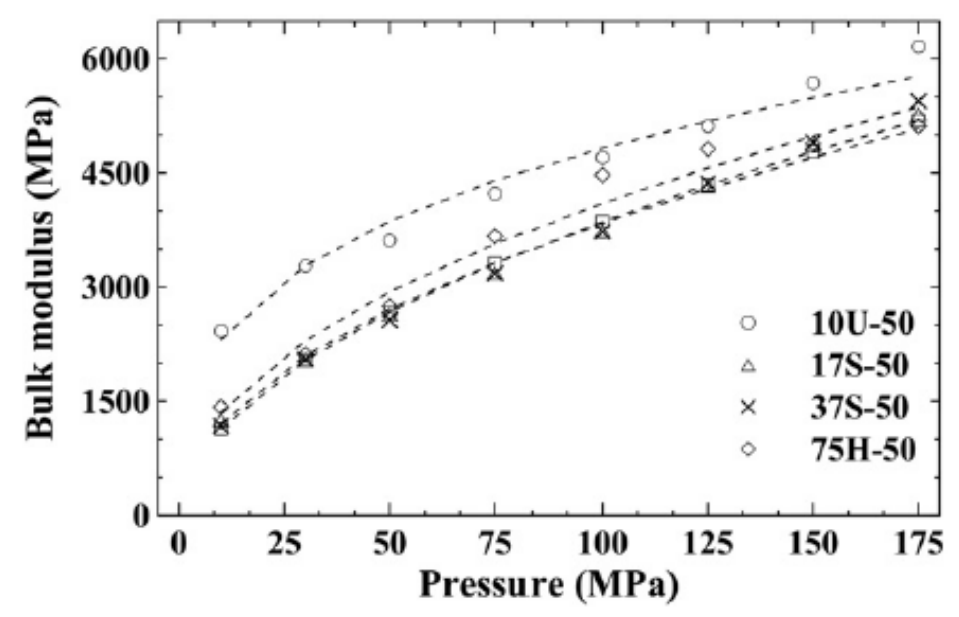

Fig. 9. Bulk modulus in the melting region as a function of pressure for various samples: effect of powder characteristics. 


\subsection{Thermal expansion coefficient}

Thermal expansion coefficient is an important parameter both in the field of polymer engineering and composites; sometimes it even defines the application range of the material. In fact, an accurate knowledge and prediction of thermal expansion coefficients (hence shrinkage) is a crucial point for an effective prevention of warpage occurrence [17]. Enhancement of dimensional stability is expected when the filler with high modulus and low thermal expansion coefficient is dispersed in a matrix of a lower modulus and higher thermal expansion coefficient owing to simple mechanical restraints.

The volumetric thermal expansion above the melting temperature of the binder without any filler is about $\left(6 \times 10^{-4}\right) 1 /{ }^{\circ} \mathrm{C}$. Linear relationship between volumetric thermal expansion coefficient and pressure was obtained ( Fig. 11). From Fig. 11 it can be seen that with an increase in the filler content, the thermal expansion coefficient decreases. As expected, the reinforcement with lower thermal expansion coefficient introduces a constraint effect on the thermal expansion of the matrix.

It should be noted that the system with the largest particle sizes $(75 \mathrm{H}$ - diameter at $10 \%, 2.19 \mu \mathrm{m} ; 90 \%$ : $28.06 \mu \mathrm{m}$ ) shows the lowest thermal expansion, while the same parameter for compounds based on the remaining three powders are rather similar (Fig. 12).

As first-order approximation, the thermal expansion coefficient may be expected to result from the rule of mixtures; the contribution of the thermal expansion of the polymer binder $\left(\alpha_{m}\right)$ and the filler $\left(\alpha_{f}\right)$, are weighed by their respective volumetric fractions $\varphi$ :

$$
\alpha=\alpha_{m}(1-\phi)+\alpha_{f} \phi
$$

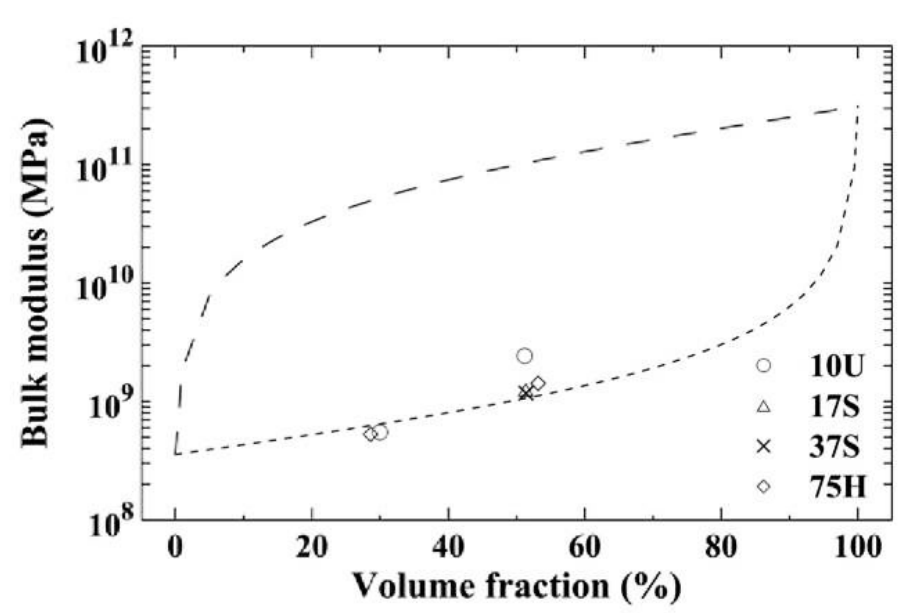

Fig. 10. Bulk modulus of the melting region of all analyzed samples. The lines represent the upper and the lower boundaries predicted by the Hashin and Shtrikman model $[12,13]$.

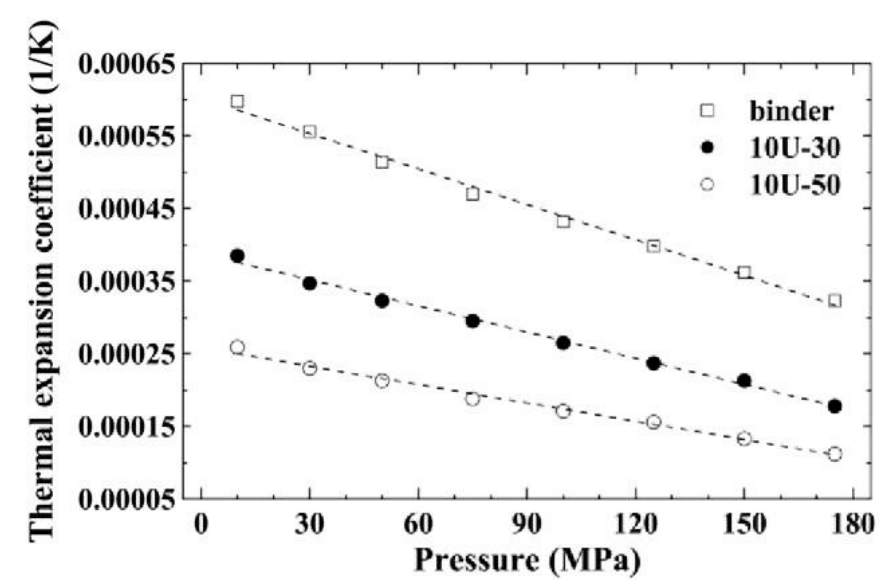

Fig. 11. Volumetric thermal expansion coefficient in the melting region of binder and 50 vol.\% filled compounds.

Turner [18] developed a model that takes into account the mechanical interaction between different materials in the composite. Based on the assumption that all phases in the composite have the same dimension change with temperature, he derived a relationship that is expressed as (Eq. (9)): 


$$
\alpha=\frac{(1-\phi) K_{m} \alpha_{m}+\phi K_{p} \alpha_{p}}{(1-\phi) K_{m}+\phi K_{p}}
$$

Based on the overall bulk modulus of the composite, Schapery [19] developed a model to predict the upper and lower bounds of the thermal expansion coefficient. The two bounds are given by:

$$
\begin{aligned}
& \alpha^{1}=\alpha_{m}+\frac{K_{p}}{K^{u}} \frac{\left(K_{m}-K^{u}\right)\left(\alpha_{p}-\alpha_{m}\right)}{\left(K_{m}-K_{p}\right)} \\
& \alpha^{u}=\alpha_{m}+\frac{K_{p}}{K^{1}} \frac{\left(K_{m}-K^{1}\right)\left(\alpha_{p}-\alpha_{m}\right)}{\left(K_{m}-K_{p}\right)}
\end{aligned}
$$

The upper and lower bounds as calculated from the Hashin- Shtrikman model (Eqs. (6) and (7)) are used to calculate the lower and upper bounds in the Eqs. (10) and (11).

Fig. 13 shows the comparison between experimental data and theoretical models for the volumetric thermal expansion coefficient in the melting region. It can be seen that for all the systems the volumetric thermal expansion coefficient obtained lies in between mixing rule and Schapery's lower bounds. The Schapery model underestimates the thermal expansion coefficient values of the composites. It could be due to the weak bonding between the filler particles and the binder that does not allow an efficient stress transfer.

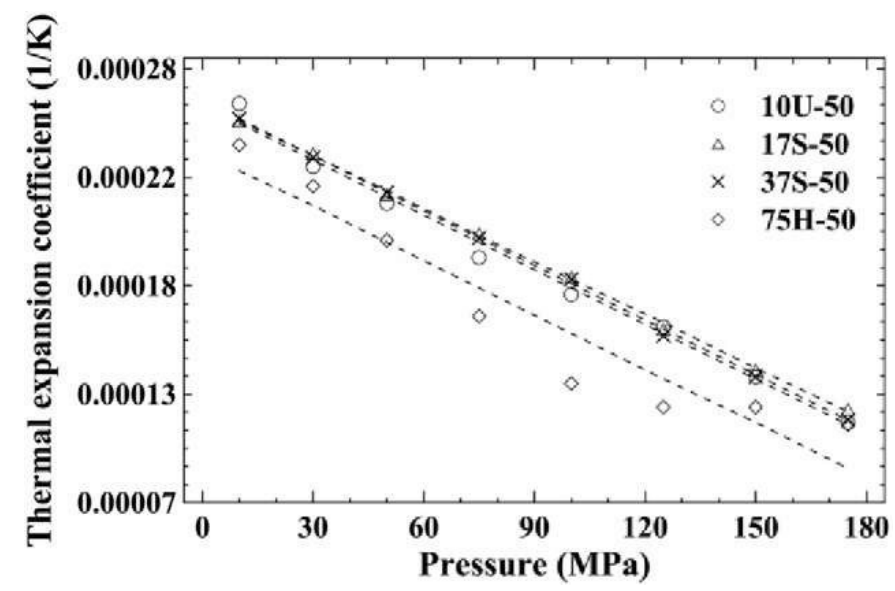

Fig. 12. Volumetric thermal expansion coefficient in the melting region of various $50 \mathrm{vol} . \%$ filled compounds.

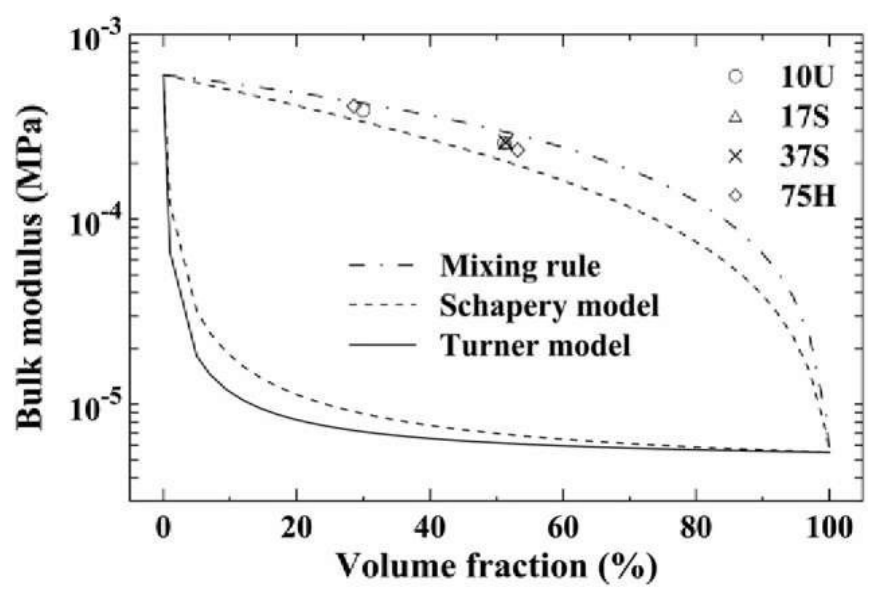

Fig. 13. Volumetric thermal expansion coefficients in the melting region as a function of filler volume fraction. The dash-pot line represents the prediction according to the mixing rule, whereas the dashed lines represent the lower and the upper boundaries of the Schapery model [16].

\section{Conclusion}

The pressure-volume-temperature characteristics of cemented carbide-based powder injection molding compounds were investigated using high-pressure mercury dilatometer. The volumetric thermal expansion coefficient and compressibility of investigated compounds become reduced as the powder amount increases up to 50 vol.\% due to a constraint effect of a filler on the thermal expansion of the binder. Whereas the cause of the pressure dependence of the volumetric thermal expansion coefficients is linear, the compressibility shows an exponential cause and at high pressures it becomes almost pressure-independent. 
According to the Hashin and Shtrikman model the stress transfer between the powder and the polymer binder can be neglected in the melting region. Further comparison of the data derived experimentally with theoretical models for the volumetric thermal expansion coefficient in the melting region reveals that for all tested compounds the measured data lies in between the mixing rule and Schapery's lower boundary reflecting the weak bonding between the filler particles and the binder.

The results obtained for four types of feedstocks differing in powders used verified that particle size distribution has an effect on the pressure-volume-temperature behavior of the compounds becoming pronounced if very fine carbide feedstock is compared with the coarsest one.

\section{Acknowledgment}

The authors would like to acknowledge the Grant Agency of the Czech Republic (project no. 103/08/1307). This article was created with support of Operational Program Research and Development for Innovations co-funded by the European Regional Development Fund (ERDF) and national budget of Czech Republic, within the framework of project Centre of Polymer Systems (reg. number: CZ.1.05/2.1.00/03.0111).

\section{References}

[1] R.M. German, Powder Injection Molding, MPIF, 1995.

[2] H. Persson, B. Hausnerova, L. Nyborg, M. Rigdahl, Rheological and thermal properties of a model system for PIM, International Polymer Processing 24 (2009) 206-212.

[3] W.-C.J. Wei, R.-Y. Wu, S.-J. Ho, Effects of pressure parameters on alumina made by powder injection moulding, Journal of the European Ceramic Society 20 (2000) 1301-1310.

[4] C.D. Greene, D.F. Heaney, The PVT effect on the final sintered dimensions of powder injection molded components, Materials and Design 28 (2007) 95-100.

[5] B. Boehme, K.M.B. Jansen, S. Rzepka, K.J. Wolter, Proceedings of the 10th International Conference on Thermal, Mechanical and Multiphysics Simulation and Experiments in Micro-Electronics and Micro-Systems, Delft, 2009, pp. 1-8.

[6] C. Binet, D.F. Heaney, R Spina, L. Tricarico, Experimental and numerical analysis of metal injection molded products, Journal of Materials Processing Technology 164-165 (2005) 1160-1166.

[7] D.R Poirier, G.H. Geiger, Transport phenomena in materials processing, Minerals, Metals and Materials Society (1994).

[8] S. Laddha, C. Wu, S. Vallury, G. Lingam, S. Lee, K. Simmons, P. Thomas, B. Levenfeld, A. Varez, S.-J. Park, S. Ahn, R.M. German, S.V. Atre, Characterization of alumina feedstock with polyacetal and wax-polymer binder systems for micro powder injection moulding, PIM International 3 (2009) 64-70.

[9] A. Chandra, A. Best, W.H. Meyer, G. Wegner, P-V-T measurements on PMMA: PbTiO3 polymer-ceramic composites with tunable thermal expansion, Journal of Applied Polymer Science 115 (2010) 2663-2667.

[10]B. Hausnerova, T. Sedlacek P. Filip, P. Saha, The effect of powder characteristics on pressure sensitivity of powder injection moulding compounds, Powder Technology 206 (2011) 209-213.

[11]B. Hausnerova, T. Sedlacek, P. Vltavska, Pressure-affected flow properties of powder injection moulding compounds, Powder Technology 194 (2009) 192-196.

[12]B. Hausnerova, T. Sedlacek, R Slezak, P. Saha, Pressure-dependent viscosity of powder injection moulding compounds, Rheologica Acta 45 (2006) 290-296. 
[13]B. Hausnerova, T. Kitano, I. Kuritka, J. Prindis, L. Marcanikova, The role of powder particle size distribution in processability of powder injection molding compounds, International Journal of Polymer Analysis and Characterization 16 (2011) 141-151.

[14]A. Sorrentino, R. Pantani, G. Titomanlio, Crystallization of syndiotactic polystyrene under high pressure and cooling rate, Macromolecular Research 18 (2010) 1045-1052.

[15]Z. Hashin, S. Shtrikman, A variational approach to the theory of the elastic behaviour of multiphase materials, Journal of the Mechanics and Physics of Solids 11 (1963) 127-140.

[16]Z. Hashin, Analysis of composite materials: a survey, Journal of Applied Mechanics 50 (1983)481-505.

[17]R Zheng, P. Kennedy, N. Phan-Thien, X.-J. Fan, Thermoviscoelastic simulation of thermally and pressure-induced stresses in injection moulding for the prediction of shrinkage and warpage for fibre-reinforced thermoplastics, Journal of Non-Newtonian Fluid Mechanics 84 (1999) 159-190.

[18]P.S. Turner, Thermal-expansion stresses in reinforced plastics, Journal of Research of the National Bureau of Standards 37 (1946) 239-250.

[19]R.A. Schapery, Thermal expansion coefficients of composite materials based on energy principles, Journal of Composite Materials 2 (1968) 380-404. 